\title{
The Impact of Corporate Venture Capital (CVC) Information Disclosure on Corporate Value
}

\author{
Yongbo Kang ${ }^{1, a}$, Susheng Wang ${ }^{1, b}, K^{2}$ Peng ${ }^{1, c}$, Yongrui Yu ${ }^{1, d}$, Junbo Wang ${ }^{1, e}$, \\ ${ }^{1}$ Shenzhen Graduate School, Harbin Institute of Technology, Shenzhen 518055, China. \\ akangyongbo@163.com, bwangsusheng@gmail.com, c1037049731@qq.com, d467313582@qq.co \\ m, e407995864@qq.com
}

Keywords: Information disclosure, corporate value, corporate venture capital.

\begin{abstract}
This paper examines the relation between CVC information disclosure and corporate value based on real option theory. We used data of CVC from 2010 to 2015, analysis value relevance of CVC information disclosure. First, this article establish a theory model to explain value relevance of CVC information disclosure. And this article point out that the value of real option embedded in corporate venture capital. Second, this article used event study method finds that CVC information disclosure can create positive return. By using multiple regression analysis, this article finds that CVC information disclosure is positively correlated with the corporate value. Our study broad knowledge on CVC information disclosure influence corporate value.
\end{abstract}

\section{Introduction}

Corporate venture capital (CVC) refers to any equity investment made by non-financial corporations in start-up companies, for both strategic and financial purpose [1, 2]. "CVC information disclosure" refers to a firm's public presentation of corporate venture capital information via many venues (e.g. regulatory filings, press releases, and company websites) [3]. Worldwide academic interest in CVC and corporate value has increased considerably over the past decade [1,4]. Many scholars find that CVC can offer real options to obtain the flexibility of technology and business resources for incumbents [5, 6]. But much less work has been done to examine the relation between CVC information disclosure and corporate value based on real option theory. In this paper we aim to partially fill this gap by empirically examined the value relevance of CVC information disclosure based on entropy weight method.

\section{Model and Hypothesis}

Based on Verrecchia's[7] simple model of information disclosure, we introduce real option theory to illustrate the value relevance of CVC information disclosure. To start, we assume that there exists some asset (e.g., a firm) whose value is uncertain, and about which some information is disclosed. Uncertainty can be represented by a random variable of any variety, but the normal distribution is well behaved mathematically and understood at an intuitive level by most researchers. Consequently, we assume that uncertain firm value is represented by a variable $\tilde{\mu}$, which has a normal distribution with mean $\mathrm{m}$ and precision (i.e., the reciprocal of variance) $\mathrm{h}$. The precision $\mathrm{h}$ can be interpreted as the market's prevailing level of common knowledge about the firm's uncertain value, $\tilde{\mu}$.

$$
\tilde{\mu} \sim \mathrm{N}\left(m, \frac{1}{h}\right)
$$

The disclosure is information about firm value, but information is less than perfect. Let disclosure be represented by $\tilde{y}=\tilde{\mu}+\tilde{\eta}$, where $\tilde{\eta}$ is also a normal distribution with mean 0 and precision $\mathrm{n}$ :

$$
\tilde{\eta} \sim \mathrm{N}\left(0, \frac{1}{\mathrm{n}}\right)
$$


We assume that all relevant issues related to disclosure can be characterized by assuming an economy with two periods: time T-1 is the period immediately before disclosure occurs, and time $\mathrm{T}$ is the time immediately after (i.e., the disclosure period). Let the prices for the assets at times T- 1 and $\mathrm{T}$ be represented by ${ }{ }_{T-1}$ and ${ }{ }_{T}$, respectively. In this model I assume that all investor agents who participate in the market are risk-neutral, can assume unlimited liability for realizations of firm value, and have no information (private or public) about firm value at time T-1. Because of the absence of information, at time T-1 all expectations are based on the unconditional expectation of $\tilde{\mu}$, which is m. Furthermore, because investor agents are risk-neutral, the price of the asset at time T-1 is $\mathrm{P}_{T-1}=\mathrm{m}$.

The difference between CVC information disclosure and other information disclosure is that CVC information disclosure makes investors realize the CVC and real option embedded in CVC. The real option offers incumbents flexibility to obtain technology and business resource. So, at time T, based on the model 1 , real option value is added to corporate value, which opt is the value of real option, and ${ }^{I^{y}}$ is an indicator function. When incumbents disclose CVC information, ${ }^{y}=1$. When incumbents didn’t disclose CVC information, $\mathrm{I}_{y}=0$.

$$
\tilde{\mu} \sim \mathrm{N}\left(m+\mathrm{opt} \cdot I_{y}, \frac{1}{h}\right), \mathrm{I}_{y}=\left(\begin{array}{c}
1, y \neq 0 \\
0, y=0
\end{array}\right)
$$

That is to say, disclosing CVC information $y \neq 0$ by incumbents, investors realize the value of real option $^{I_{y}=1}$. Then corporate value is increased by opt. But if incumbents don't disclose CVC information $\mathrm{y}^{\mathrm{y}} 0$, investors can't realize the value of real option ${ }^{y}=0$, corporate value is unchanged ultimately. At time $\mathrm{T}$, incumbents disclose $\mathrm{CVC}$ information $\tilde{\mathrm{y}}=\mathrm{y}$. Investors analyze CVC information, and update the value estimate of incumbents. According to conditional expectation formula of bivariate normal distribution, we can be derived:

$$
\mathrm{P}_{t}=\mathrm{E}[\tilde{\mu} \mid \tilde{\mathrm{y}}=\mathrm{y}]=\mathrm{m}+\mathrm{opt}+[\mathrm{n} /(\mathrm{h}+\mathrm{n})] \cdot(\mathrm{y}-\mathrm{m}-\mathrm{opt})
$$

Accordingly, the price change from time $\mathrm{T}$ to time $\mathrm{T}-1$ is:

$$
\mathrm{P}_{T}-\mathrm{P}_{T-1}=[\mathrm{n} /(\mathrm{h}+\mathrm{n})] \cdot(\tilde{\mathrm{y}}-\mathrm{m})+[\mathrm{h} /(\mathrm{h}+\mathrm{n})] \cdot \mathrm{opt}
$$

According to the above derivation, we can get the following enlightenment: (1) we find that disclosure response coefficient (DRC) in the change in price is $\mathrm{n} /(\mathrm{h}+\mathrm{n})$. The higher the level of CVC information disclosure, the higher the value of the corporate; (2) compared to other information disclosure, there exists real option in CVC disclosed by incumbents. The value of real option will be added to corporate value. Thus,

Hypothesis 1: the behavior of CVC information disclosure will enhance the corporate value.

Hypothesis 2: the greater level of CVC information disclosure, the higher value of corporate.

Hypothesis 2a: the greater level of CVC information disclosure, the higher short-term value of corporate.

Hypothesis 2b: the greater level of CVC information disclosure, the higher long-term value of corporate.

\section{Data and Method}

We obtain CVC announcement downloaded from website www.cninfo.com.cn. we select the data selection period from 2010 to 2015. Data source for other variables were obtained from WIND database. we had an sample that consisted of 419 CVC program.

According to Shanghai and Shenzhen Stock Exchange regulation documents, We define CVC information disclosure index . There is 33 indicators (due to the limted pages, we didn't list them). If incumbents quantitatively disclose CVC information, we set 3 points. If incumbents qualitative 
disclose CVC information, we set 1points. If incumbents don't disclose any information, we set 0 points. Finally, we sum indicator scores:

$$
I D Q_{\mathrm{j}}=\sum_{i=1}^{n} \text { indicator } \quad x_{i, j}
$$

Other variables is defined in table 1.

Table 1 variables define

\begin{tabular}{ccl}
\hline & variables & \multicolumn{1}{c}{ Explanation of variables } \\
\hline \multirow{2}{*}{ Explained variable } & Tobin & Tobin Q as long-term corporate value \\
Explanatory variable & ACAR & Accumulate abnormal returns \\
& IDQ & CVC information disclosure index \\
& ASSET & Company size, measured as the natural logarithm of the firm's total assets \\
& at the end of the announcement day's last fiscal year \\
Control variable & INCOME & Company growth ability, measured as company income growth rate \\
& LEV & Asset liability ratio \\
& ROE & Profitability of company, net income/company income \\
& SHARE & Proportion percent of large shareholders \\
& INVEST & Beta calculated by the CAPM model \\
\hline
\end{tabular}

We construct multivariate model as follows:

Tobin $=c+\beta I D Q+\gamma C O N T R O L+\varepsilon$

$\mathrm{ACAR}=c+\beta I D Q+\gamma C O N T R O L+\varepsilon$

CONTROL is control variable in table 2 .

\section{Main results}

Table 2 reports the abnormal return of CVC information disclosure by using event study method. $\operatorname{ACAR}(-5,10)$ is $7.412 \%$ at $1 \%$ significant level. It means that the behavior of CVC information disclosure will enhance the corporate value. We also examine the ACAR in different time window. They are also significant positive at $1 \%$ level.

Table 2 Abnormal return of CVC information disclosure

\begin{tabular}{ccrrr}
\hline No & window & ACAR & T-stat & \multicolumn{1}{c}{ P-value } \\
\hline 1 & $(-5,10)$ & $7.412^{* * *}$ & 4.890 & 0.000 \\
2 & $(-5,5)$ & $6.919 \%^{* * *}$ & 5.805 & 0.000 \\
3 & $(-3,3)$ & $5.378 \%^{* * *}$ & 5.200 & 0.000 \\
4 & $(0,10)$ & $6.278 \%^{* * *}$ & 4.922 & 0.000 \\
5 & $(0,5)$ & $5.785 \%^{* * *}$ & 5.620 & 0.000 \\
6 & $(0,3)$ & $4.636 \%^{* * *}$ & 5.254 & 0.000 \\
7 & $(-1,1)$ & $3.482 \%^{* * *}$ & 5.649 & 0.000 \\
\hline
\end{tabular}

Note: *** represents $1 \%$ significance; ** represents $5 \%$ significance; * represents $10 \%$ significance.

Table 3 reports the results of multiple regression analysis results. Model 1-3examines the short-term value relevance of CVC information disclosure. The ACAR window time is $(-5,10),(5,5)$ and $(-3,3)$. For example $(-3,3)$ means that the accumulated abnormal return from three days before information disclosure day to three days after information disclosure day. In model 1 show a positive association between ACAR $(-5,10)$ and IDQ at 1\% level. In model 2 show a positive association between ACAR $(-5,5)$ and IDQ at $5 \%$ level. It means that the greater level of CVC information disclosure, the higher short-term value of corporate. The data provides support for H2a. But in model 3 IDQ has a positive but insignificant association with ACAR(-3, 3). In model 4 show a positive association between Tobin and IDQ at $10 \%$ level. It means that the greater level of CVC information disclosure, the higher long-term value of corporate. The data provides support for H2b. 
Table 3 Multiple regression analysis results

\begin{tabular}{|c|c|c|c|c|}
\hline & $\begin{array}{c}\text { Model } 1 \\
\text { ACAR }(-5,10)\end{array}$ & $\begin{array}{c}\text { Model } 2 \\
\text { ACAR(-5,5) }\end{array}$ & $\begin{array}{c}\text { Model } 3 \\
\text { ACAR(-3,3) }\end{array}$ & $\begin{array}{c}\text { Model } 4 \\
\text { Tobin }\end{array}$ \\
\hline $\mathrm{C}$ & $-483.01 * *$ & $-355.13^{*}$ & -223.03 & $5083.35 * * *$ \\
\hline IDQ & $3468.80 * * *$ & $2156.41 * *$ & 907.98 & $5602.06^{*}$ \\
\hline ASSET & 17.73 & 14.59 & 8.10 & $-216.78 * * *$ \\
\hline INCOME & 0.01 & -0.06 & -0.07 & $0.82^{*}$ \\
\hline LEV & $0.97 * *$ & 0.48 & $0.76^{* *}$ & $-5.81 * * *$ \\
\hline ROE & -0.01 & 0.28 & 0.97 & $14.62 * * *$ \\
\hline SHARE & 0.55 & 0.11 & $0.63 *$ & -0.48 \\
\hline INVEST & 3.17 & 3.40 & 3.27 & -8.91 \\
\hline VOLUME & -0.13 & -0.30 & -0.32 & $4.69 * *$ \\
\hline R-squared & 0.07 & 0.05 & 0.07 & 0.35 \\
\hline Adj R-squared & 0.05 & 0.02 & 0.04 & 0.33 \\
\hline Prob(F-statistic & & & & \\
\hline ) & 0.01 & 0.12 & 0.01 & 0.00 \\
\hline
\end{tabular}

Note: *** represents $1 \%$ significance; ** represents $5 \%$ significance; * represents $10 \%$ significance.

\section{Conclusions}

This paper examines the relation between CVC information disclosure and corporate value based on real option theory. We used data of CVC from 2010 to 2015, analysis value relevance of CVC information disclosure. First, this article establish a theory model to explain value relevance of CVC information disclosure. And this article point out that the value of real option embedded in corporate venture capital. Second, this article used event study method finds that CVC information disclosure can create positive return. Last, CVC information disclosure index is established. By using multiple regression analysis, this article finds that CVC information disclosure is positively correlated with the corporate value. Our study broad knowledge on CVC information disclosure influence corporate value.

\section{Acknowledgment.}

This work is partially supported by National Natural Science Foundation of China (71103050). The authors also gratefully acknowledge the helpful comments and suggestions of the reviewers, which have improved the presentation.

\section{References}

[1] V. K. Narayanan, Y. Yang and S. A. Zahra, Corporate venturing and value creation: A review and proposed framework, Research Policy, vol. 38, pp. 58-76, 2009.

[2] S. A. Allen and K. T. Hevert, Venture capital investing by information technology companies: Did it pay? Journal of Business Venturing, vol. 22, pp. 262-282, 2007.

[3] J. W. Tucker and X. Zhang, Corporate disclosure and research opportunities in China, China Journal of Accounting Studies, pp. 1-14, 2016.

[4] T. J. Chemmanur, E. Loutskina and X. Tian, Corporate Venture Capital, Value Creation, and Innovation, Review of Financial Studies, vol. 27, pp. 2434-2473, 2014.

[5] V. Van de Vrande and W. Vanhaverbeke, How Prior Corporate Venture Capital Investments Shape Technological Alliances: A Real Options Approach, Entrepreneurship Theory and Practice, vol. 37, pp. 1019-1043, 2013.

[6] T. W. Tong and Y. Li, Real Options and Investment Mode: Evidence from Corporate Venture Capital and Acquisition, Organization Science, vol. 22, pp. 659-674, 2011. 
[7] R. E. Verrecchia, Essays on disclosure, Journal of Accounting and Economics, vol. 32, pp. 97-180, 2001. 